\title{
The modelling and introductions of new type ribs of lattice of the two cylinder of gin
}

\author{
Shuhrat Azizov ${ }^{1, *}$, Muhammadaminhon Ibrohimov $^{1}$, Farhod Uzoqov $^{1}$, and Mirshoroffiddin \\ Mirzakarimov ${ }^{1}$ \\ ${ }^{1}$ Namangan Institute of Engineering and Technology, str. Kasansay 7, Namangan, 160115, \\ Uzbekistan
}

\begin{abstract}
Using the above data on the manufacture of grates and taking into consideration the bending vibrations of the saw cylinders and displacement of the grates under dynamic load. Taking into account the primary factors of sectional and individual grates ribs also in order to prevent cross-displacement of grates ribs. We modeled and introduced a new type of grates ribs for a single- chamber and two-cylinder gin, which is comprised of the top and bottom, grates ribs aligned with three brackets and tightening laths with a new type of fastening respectively. In the article, consider the simulated static load experimental model of a new grate ribs lattice, which allows eliminating lateral. Displacement of ribs at dynamic loading.
\end{abstract}

\section{Introduction}

It is known that the grate of ribs is one of the most important parts of the working chamber. And its purpose is to pass the saw blades through the gaps between the grates ribs into the working chamber and free removal from the working chamber of the fiber torn from the seeds by the [1]. In the working passage of the saws, seeds should not pass through the gaps between the grates ribs together with the fibers. To the grate bars, the grates ribs are attached with the help of the screws with the heads in the countersunk.[2] Thus, the grate ribs lattice is assembled from separate grates ribs, each of which is independently attached to the [3]. This method of forming the grate ribs lattice, due to the large volume of fitting work, tends to be laborious and requires high qualifications of the assembler. But individual grate bars ribs have justified themselves in manufacturing and operation, where it is compulsory to carry out a quick replacement. A sectional grate ribs lattice is composed of separate sections, each of which replaces several other grates ribs. With the sectional method of forming the grate ribs lattice, the amount of fitting work is reduced, but their production becomes more complicated, and in operation, even if one grate ribs breaks down, it is vital to replace the entire section, which increases the cost of repair work. The conducted research has shown that the more discs are adjusted on the saw cylinder. The more longevity and endurance of grates ribs are deteriorated. This phenomenon is prompted and facilitated by the uneven bending vibration of the saw cylinder. As a result, the grates ribs are exposed to the negative impact of the saw blades. [4,5]

\footnotetext{
*Corresponding author: azizovshuhrat@gmail.com
} 


\section{Materials and Methods}

Considering the above-mentioned factors, it is of a great interest to study the lateral displacement of grates ribs, especially when they are loaded from the side of the raw roller. Some relevant studies have been conducted to determine the lateral displacements of grates ribs on an elastic foundation. Thus, they were carried out in the manufactured installation; the diagram of which is shown in Figure. 1 and the research methodology was as follows: on the brackets, imitating grate ribs bars were installed . [6,7]

No.1, whereas on an elastic base a grate ribs itself was installed No. 2. It is known that a pressure of up to $40 \mathrm{H}$ is exerted on the grate ribs from the side of the raw roller, therefore, the aforementioned researchers applied loads in the range from 0.1 to $45 \mathrm{H}$ to the lateral side of the grate ribs on its working part.[8]

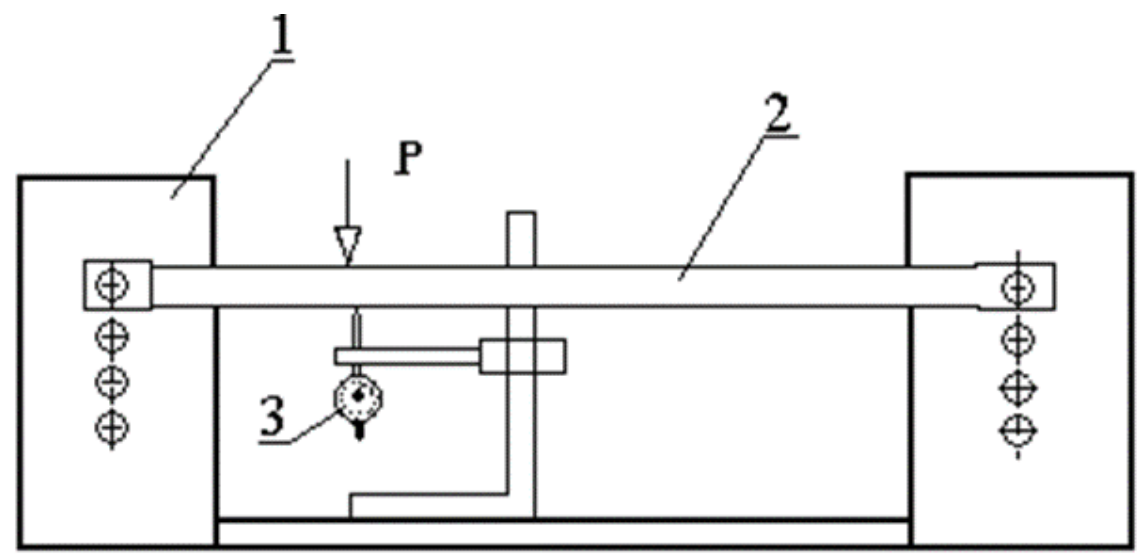

Fig. 1. Experimental setup for studying the displacement of the grate ribs, where: 1- bracket, 2- grate ribs, 3 - indicator.

The resulting lateral displacement of the grate ribs on the elastic base was measured while using a dial indicator 3, with a measurement accuracy of $0.01 \mathrm{~mm}$. The transversal displacement of the grate ribs was determined at its four positions, when it was tightly fixed to the bracket (for the purpose of comparison), and loosely fixed through the elastic base. Accordingly, the experiments were conducted at least triple times.[9,10]

From the outcomes of the experiments in Figure. 2, we can see that with a rigid fastening of the grate without the usage of an elastic base, the cases are almost not observed in regard to a transverse displacement of the grate ribs. And when the grate is firmly fixed to an elastic base, such displacements, depending on the imposed load, can reach a value of $0.130 \mathrm{~mm}$. With a loose fixing of the grate ribs, the elastic base of the lateral displacement reaches 0.20 $\mathrm{mm}$, which tends to be undesirable from the point of view of maintaining an inter-grate interribs gap of $3 \pm 0.2 \mathrm{~mm}$.

Hereby, an implementation of this study will substantially help and enable to reduce the damage of the fibers as well as seeds of the raw cotton. Consequently, on the one side it can protect the grade of the fiber along with its foreign exchange value in the international market. On the other side, this paradigm can preserve the quality of primary raw materials for the textile industry that will directly be reflected on the quality of textile products. $[11,12]$. 


\section{Analise}

In addition, a decrease in the number of faces of raw cotton in the grate ribs lattice will lead to a decline in the downtime of technological equipment, and in its turn, this will contribute to the increase of the productivity of ginning. To this should be added the energy savings on the saw gin drive, because the faces of raw cotton in the grate ribs lattice causes a significant increment in the electricity consumption required to overcome the increased resistance to the rotation of the saw cylinder.

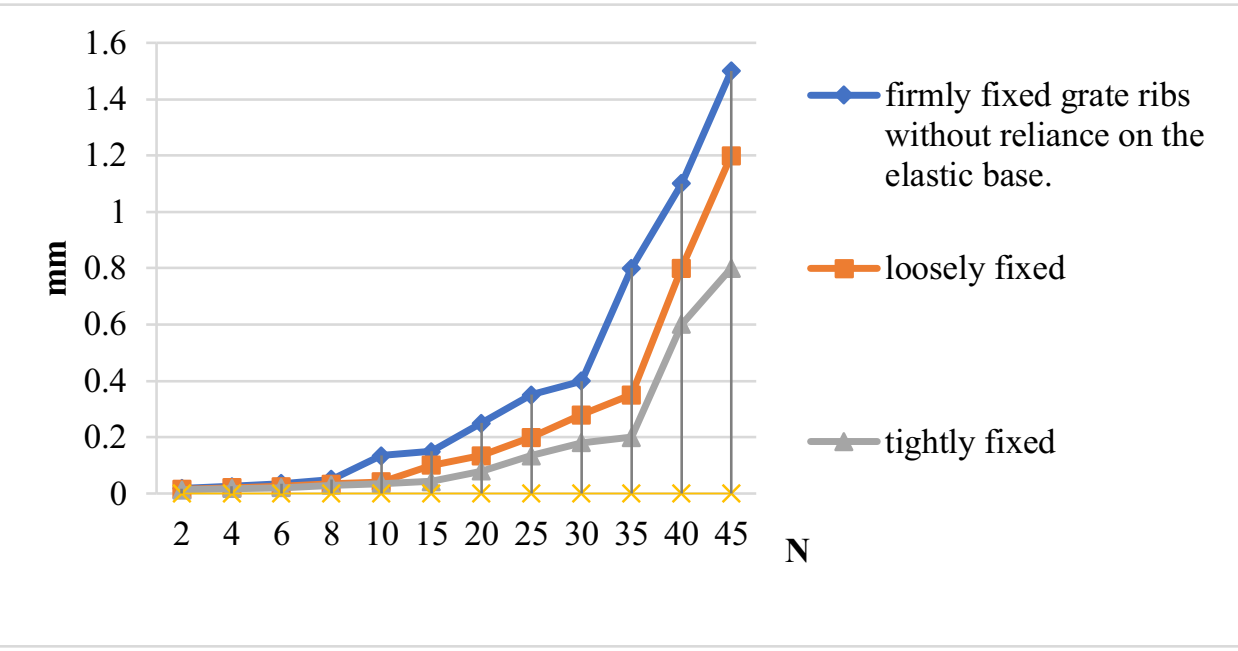

Fig. 2. Dependencies of the lateral displacements of the grate ribs from the imposed load.

The grate ribs on the elastic base: 1 - firmly fixed grate ribs without reliance on the elastic base; 2- loosely fixed; 3- tightly fixed; 4- new simulated collapsible and experimental grate ribs lattice

As on the grate ribs, from the side of the raw roller, there is a pressure from $30 \mathrm{H}$ to $50 \mathrm{H}$. Moreover, there can occur the lateral mixing of grates ribs. Even as an outcome of a tight fastening of the grate ribs to the elastic base, such displacements, depending on the applied load, can reach a value of $0.130 \mathrm{~mm}$.

\section{Results and Discussions}

Using the above data on the manufacture of grates and taking into consideration the bending vibrations of the saw cylinders and displacement of the grates under dynamic load. Taking into account the primary factors of sectional and individual grates ribs and in order to prevent cross-displacement of grates ribs.

We have developed, modeled and introduced a new type of grates ribs for a singlechamber and two-cylinder gin, which is comprised of the top and bottom grates ribs aligned with three brackets and tightening laths with a new type of fastening respectively. $[13,14]$ 
Fig. 3. demonstrates a three-dimensional view of the grate ribs lattice along with its components. The advantage of this grate ribs is that the ends of the grate ribs are made in the form of square rods that fit tightly into the slots of the bracket and are attached from above with a tightening lath. Since the grooves and the rod are in a square shape and fit tightly into each other, thus the grates ribs are prevented from an excessive displacement that will assist in reducing of the damage of the fibers and seeds of raw cotton. The width of the grate ribs is composed of $20 \mathrm{~mm}$, which is solely modeled to obtain a high-quality fiber.[15,16]

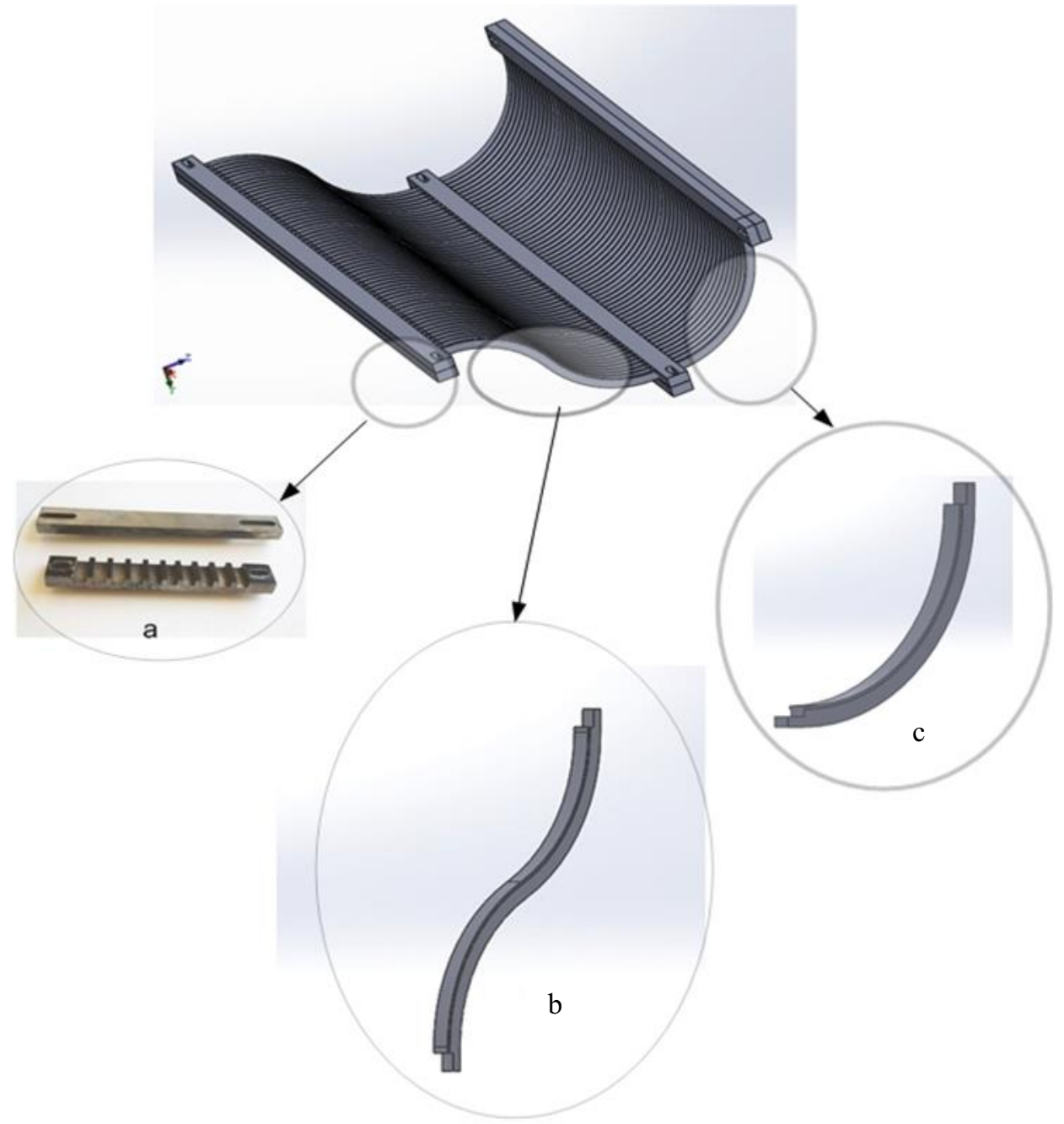

Fig. 3. New simulated collapsible and experimental grate ribs lattice. Where: a- bracket with a tightening lath, b- bottom grate ribs, в - top grate ribs. 


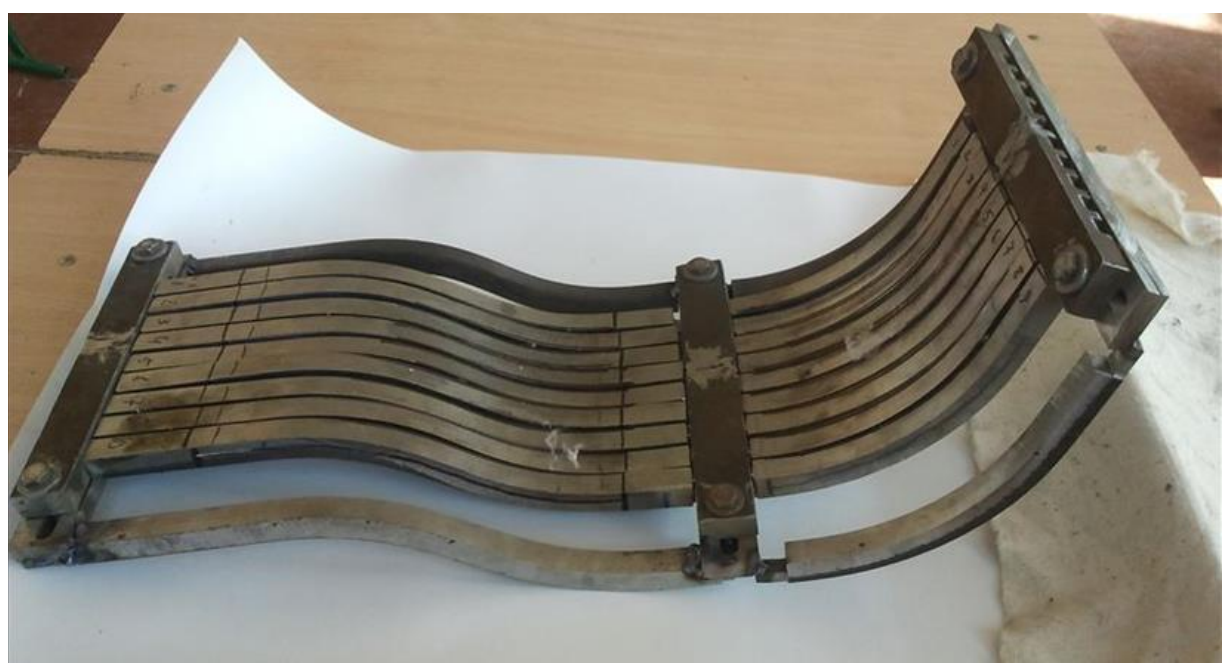

Fig. 4. New grate ribs lattice in the assembled form.

To confirm the correctness of the insertion of a new simulated experimental sample of the grate ribs, we conducted a scientific experiment on the displacement of grates ribs by using the method of scientists of the Tashkent Institute of Textile and Light Industry for individual grates ribs, which are attached to the bars with the help of countersunk head screws. [17,18]

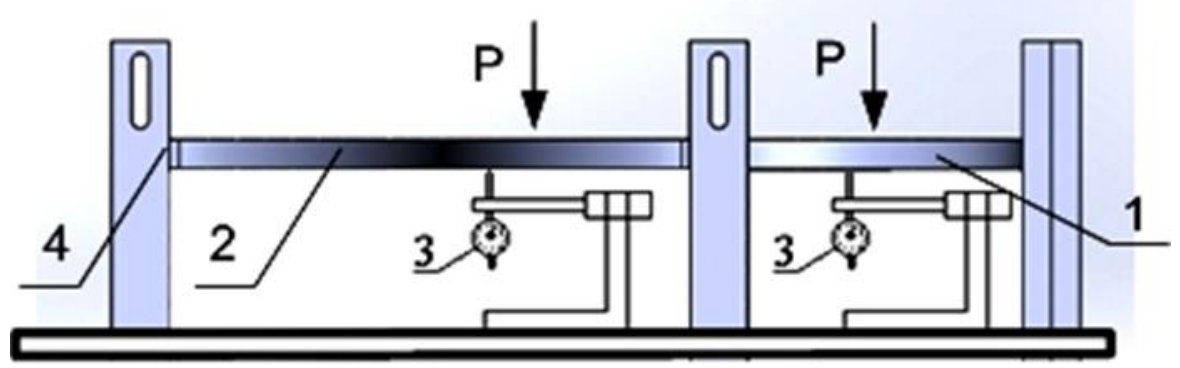

Fig. 5. Experimental setup for the study of a new type of grate ribs on the lateral Displacement of the grate ribs. Where:1- top grate ribs, 2- bottom grate ribs, 3-indicator, 4- bracket with a tightening lath.

As our grates are not attached to the bars, with the help of screws we dismantled the brackets and a tightening lath and removed all the top and bottom grates ribs, leaving only one upper and lower grate ribs. And later placed them tightly on the square slots of the bracket and clamped them from above with a tightening lath, after that we have begun conducting an experiment.[19], [20].

The experiments were carried out several times. From the results of the studies on Figure 5 , it can be witnessed that, when the grate ribs is firmly seated on the bracket slots and tightened with laths, the case of a lateral displacement of the grate ribs is not observed. 


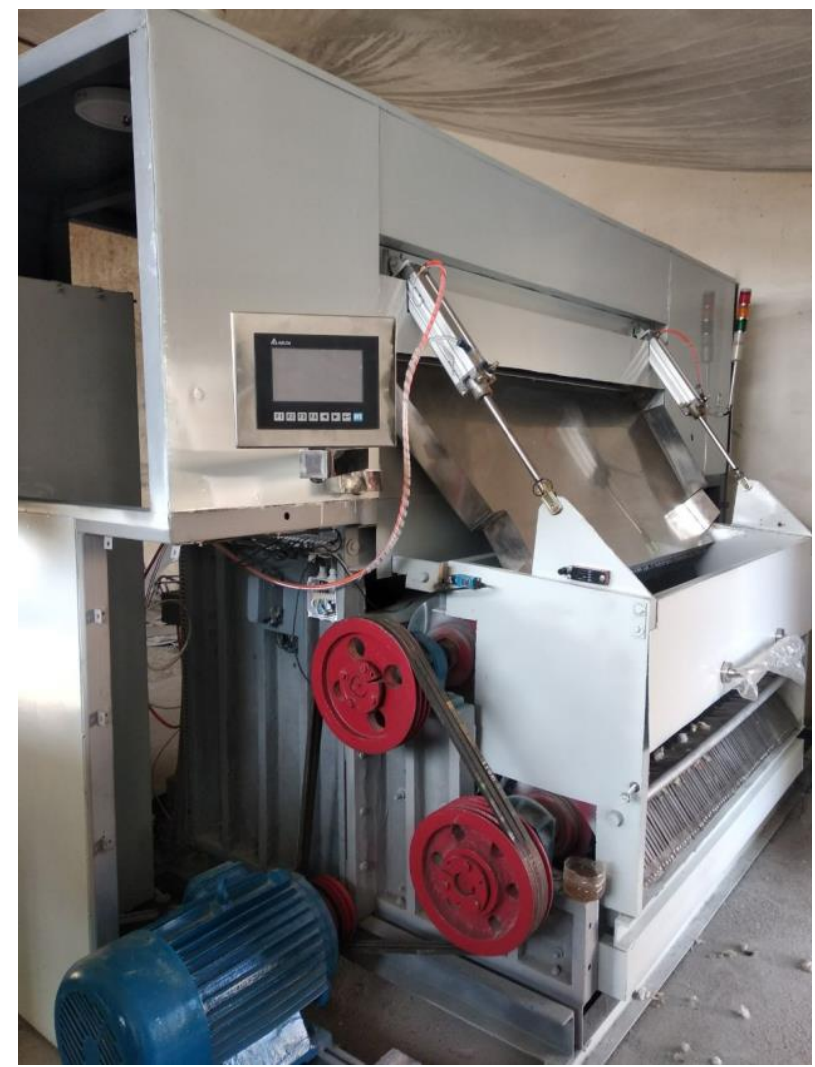

Fig. 6. Location of the grate ribs lattice on the experimental stand.

\section{Conclusion}

The introduction of simulated new types of grates ribs of a single-chamber and doublecylinder gin will reduce the damage of the fibers and seeds of raw cotton. Hereby, as a consequence, it will help to preserve the grade of fiber and its foreign exchange value in the international market, as well as maintain the quality of primary raw materials for the textile industry, which will directly impact on the very quality of textile products.

Besides, a decrease in the number of faces of the raw cotton in the grate ribs will lead to a dwindle in the downtime of technological equipment, which will in its turn generate an increase in ginning productivity. To this should be added energy savings on the drive of the saw gins, since the faces of the raw cotton in the grate ribs lattice causes a dramatic increase in electricity consumption required to overcome the increment forces of resistance to rotation of the saw cylinder.

\section{References}

1. S.M. Azizov, X. T. Axmedhodjaev, The Optimal Modeling of an Angular Position of Saw Cylinders in Single-Chamber Two Cylinders Gin, http://www.sciencepublishinggroup.com, vol. 1, no. 3, p. 103, Nov. 2016.

2. E.A. Normatov, AA. Safoev, Namangan Institute of Engineering scientifically journal 1(3) (2015) 
3. S.M. Azizov, J. Material Sci. Eng. 2(4) (2013)

4. C.B. Armijo et al., ENGINEERING AND GINNING How Current Cotton Ginning Practices Affect Fiber Length Uniformity Index, Journal of Cotton Science (2019)

5. A.S. Mamatovich, K. Abdusamat, and P. Arras, World J. Mech. 03(01), 58-61 (2013)

6. K. Sharipov, K. Akhmedxodjayev, M. Tojiboyev, and O. Sarimsakov, Engineering journal 12(03), 216-227 (2020)

7. A.S. Mamatovich, 3rd Int. Conf. Exhib. Mater. Sci. Eng. Hilt. San Antonio Airport, USA 79, 20-2020 (2014)

8. S.M. Azizov, Journal. Mater. Sci. Eng. s2(01) (2013)

9. K.A. Ismonovich, A.I. Alateyah, H. N. Dhakal, and Z.Y. Zhang, Journal. Mater. Sci. Eng. s2(01) (2013)

10. H. Wang,S. Dong, Research on the Coupled Axial-Transverse Nonlinear Vibration of Sucker Rod String in Deviated Wells, Journal Vib. Eng. Technol. (2020)

11. M. Patel, D.K. Dubey, and S.P. Singh, Mater. Sci. Eng. C 108 (2020)

12. F.A. Esteve-Turrillas and M. de la Guardia, Resour. Conserv. Recycle journal 116, 107115 (2017)

13. E. Hughs and G. Holt, Ginning, Journal of Cotton Science (2015)

14. Y. Zhang and H. Dong, Yield and Fiber Quality of Cotton, Encyclopedia of Renewable and Sustainable Materials, Elsevier, 356-364 (2020)

15. Sh.M. Azizov, Analysis of the stress state of a two-cylinder saw gin, Mechanical problems journal (2016)

16. Sh. Azizov, A. Karimov, Mathematical Modeling Of the Technological Processes Original Processing Of Cotton, International Journal of Innovation and Applied Studies (2014)

17. K. Sartova, E. Omurzak, G. Kambarova, I. Dzhumaev, B. Borkoev, and Z. Abdullaeva, Diam. Relat. Mater Jour. 91, 90-97 (2019)

18. F. Hosseinali and J. A. Thomasson, Tribol. Int. jour 127, 433-445 (2018)

19. F. Wang and Y. Q. Zhang, Mater. Sci. Eng. C 74, 152-158 (2017)

20. H. Zhang, H. Li, H. Liu, D. A. Lang, H. Xu, and H. Zhu, Int. Biodeterior. Biodegrade journal 142, 124-130 (2019) 